\title{
The restricted surgical relevance of morphologic criteria to classify systemic-pulmonary collateral arteries in pulmonary atresia with ventricular septal defect
}

Now that systemic-pulmonary collateral arteries are used for unifocalization in patients with pulmonary atresia and ventricular septal defect, the question arises whether morphologic criteria of these collateral arteries could help to provide better results. In an attempt to classify the morphologic features of systemic-pulmonary collateral arteries, we studied 31 heart-lung autopsy specimens with pulmonary atresia and ventricular septal defect. The course of the systemic-pulmonary collateral arteries (origin, branching pattern, and connections with systemic and central pulmonary arteries) was related to their histologic characteristics. The results show that systemic-pulmonary collateral arteries cannot be classified according to their course related to the trachea and the main branches of the bronchi. The histologic features of these collateral arteries vary along their course to the lungs. Nearly all systemic-pulmonary collateral arteries contain a muscular or a musculoelastic segment. One type of collateral artery (complex loop anastomoses) is completely muscular and resembles a bronchial artery. Nutritive branches (bronchial arteries) arise from all histologic types of systemic-pulmonary collateral artery segments. The size and number of intimal proliferations in muscular, elastic, and musculoelastic segments did not differ significantly. In 29 of 31 cases a ductus arteriosus did not coexist with large collateral arteries (two cases unknown). It is concluded that a classification of large systemicpulmonary collateral arteries based on morphologic features results in a highly variable system, which does not facilitate decisions for the suitability of these arteries for unifocalization procedures. The variability of the systemic-pulmonary collateral arteries corresponds with the recent embryologic finding that during development, collateral artery formation is possible during extended periods. ( $\mathrm{J}$ Thorac Cardiovasc SuRG 1994;108:692-9)

M. C. DeRuiter, PhD, A. C. Gittenberger-de Groot, PhD, Leiden, A. J. J. C. Bogers, MD, PhD, Rotterdam, and N. J. Elzenga, MD, PhD, Groningen, The Netherlands

From the Department of Anatomy and Embryology, University of Leiden, Leiden, The Netherlands; Thoracic Surgery, University Hospital Dijkzigt, Rotterdam, The Netherlands; and Pediatric Cardiology, University Hospital Groningen, Groningen, The Netherlands.

Supported by the Netherlands Heart Foundation (grant 87062).

Received for publication March 2, 1994.
Accepted for publication May 23, 1994.

Address for reprints: M. C. DeRuiter, PhD, Department of Anatomy and Embryology, University of Leiden, P.O. Box 9602, 2300 RC Leiden, The Netherlands.

Copyright 1994 by Mosby-Year Book, Inc.

$0022-5223 / 94 \$ 3.00+0 \quad \mathbf{1 2} / \mathbf{1} / \mathbf{5 7 7 8 2}$

692 
In patients with pulmonary atresia the blood supply of the lungs is derived from the systemic arterial circulation through a ductus arteriosus, through collateral arteries, or through both routes. ${ }^{1-5}$ Various terms have been suggested to describe these collateral arteries: bronchial arteries, ${ }^{6}$ systemic arteries, ${ }^{7}$ systemic collateral arteries, ${ }^{8}$ systemicpulmonary arteries, ${ }^{5}$ and major aortopulmonary collateral arteries. ${ }^{9} \mathrm{We}$ prefer to use the term systemic-pulmonary collateral arteries, as suggested by McGoon and coworkers, ${ }^{10}$ for any arterial vessel other than the ductus arteriosus, which compensates the obstructed blood flow from the right ventricle to the pulmonary arteries.

Many investigators distinguish two types of collateral supply to the lungs. The first consists of a group of small and tortuous systemic-pulmonary collateral arteries with a multifocal origin from the aorta and its branches. They are often associated with well-developed central pulmonary arteries? These systemic-pulmonary collateral arteries are probably acquired postnatally to achieve a greater pulmonary flow., ${ }^{21-13}$ The other collateral supply consists of large systemic-pulmonary collateral arteries, sometimes associated with absent or hypoplastic central pulmonary arteries, ${ }^{7}$ and is considered to be of congenital origin. ${ }^{14}$ In contrast to the small, tortuous systemic-pulmonary collateral arteries, ${ }^{11}$ the large collateral arteries often connect with hilar or intrapulmonary arteries and are fewer in number. ${ }^{7}$

Large systemic-pulmonary collateral arteries are believed to be persistent embryonic ventral splanchnic arteries or enlarged bronchial arteries. ${ }^{15-17}$ This possibly different embryonic origin of the collateral arteries has led to a classification on the basis of the site of anastomosis with the pulmonary arteries. ${ }^{18,19}$ However, such a classification appears to be an oversimplification in the light of other recent reports. For instance, Haworth and Macartney ${ }^{9}$ stated that bronchial arteries and large systemicpulmonary collateral arteries were two distinctly separate systems, although Liao and coworkers ${ }^{2}$ showed that small nutritive branches to the bronchi (bronchial arteries) can also arise from the large collateral arteries.

A normal pulmonary blood flow can be obtained in case of pulmonary atresia with large systemic-pulmonary collateral arteries by surgical reconstruction of the obstructed right outflow tract in combination with unifocalization of the pulmonary blood supply. Unifocalization is a prerequisite for successful surgical treatment of pulmonary atresia with ventricular septal defect and large systemicpulmonary collateral arteries. ${ }^{20-22}$ Unifocalization can be defined as the surgical procedures directed toward elimination of the multiple extracardiac sources of pulmonary arterial blood flow, the restoration of complete lobar and segmental pulmonary arterial blood flow, adequate enhancement of hypoplastic segments or replacement of missing segments of the central pulmonary arteries, and the creation of a central, single, and accessible source of pulmonary flow. ${ }^{21,22}$

Intimal proliferation can develop to varying degrees along the course between the origin and the peripheral pulmonary bed of the systemic-pulmonary collateral artery, eventually resulting in a stenosis. ${ }^{21-25}$ Progressive intimal proliferation is thought to play a role, resulting in luminal constriction. ${ }^{21,} 22$ These stenoses may protect the intrapulmonary arterial bed from pulmonary hypertensive vasculopathy but can clearly prevent successful unifocalization. ${ }^{22,25}$ Although surgical procedures are described to deal with these stenoses, ${ }^{24,25}$ it is not clear whether these result in long-term successful patency of the pulmonary vascular segment.

In the present study we attempted to clarify the morphology of the collaterals to possibly facilitate a better result in patients undergoing these complicated staged surgical procedures. The course of systemic-pulmonary collateral arteries was related with the histologic characteristics of the tunica intima and media. Specific attention was paid to the presence of a ductus arteriosus, normal bronchial arteries, nutritive branches from systemic-pulmonary collateral arteries to the bronchi, and to the presence of intimal proliferations. The results are discussed in view of recently described embryologic data on pulmonary and bronchial artery formation on the one hand and in view of the suitability for incorporation in surgical reconstruction of the pulmonary arterial system on the other hand.

\section{Material and methods}

In the Children's Hospital of Pittsburgh the vascular patterns of large systemic-pulmonary collateral arteries in heart-lung autopsy specimens in 11 cases of pulmonary atresia with ventricular septal defect were studied. The ages of the patients from whom the specimens were retrieved ranged from 1 day to 22 months. Only two patients underwent an operation; both died within 3 days. It was possible to investigate the extrapulmonary course and the proximal part of the intrapulmonary course of the systemic-pulmonary collateral arteries and the pulmonary arteries relative to the trachea and bronchi. The presence of a ductus arteriosus, bronchial arteries, and anastomoses between the systemic-pulmonary collateral arteries and the pulmonary arteries were recorded. The histologic characteristics of the arteries could not be evaluated, however.

In the Mayo Clinic at Rochester, Minnesota, 20 heart-lung autopsy specimens of pulmonary atresia with ventricular septal defect were available. The ages of the patients ranged from 26 days to 30 years. This material belonging to a larger group $(n=31)$ of autopsy specimens has been described previously by Liao and coworkers. ${ }^{2}$. The existing drawings of their work showed the course and branching pattern of the large systemicpulmonary collateral arteries relative to the bronchi. The histo- 


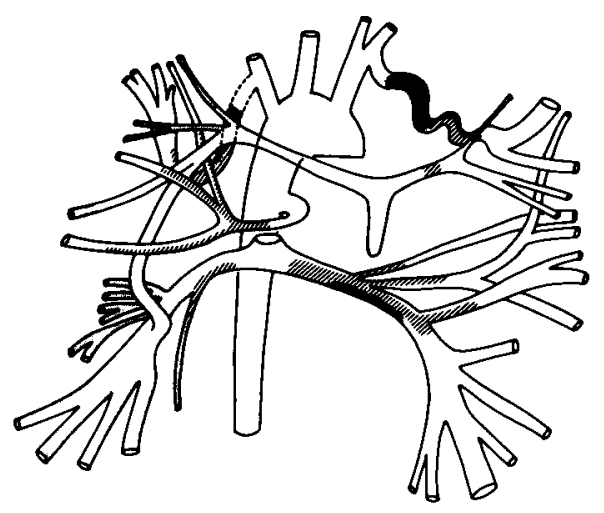

$1 \mathrm{~A}$

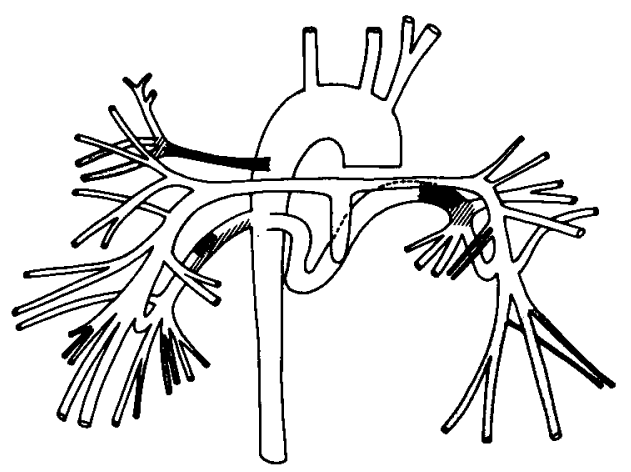

$1 B$

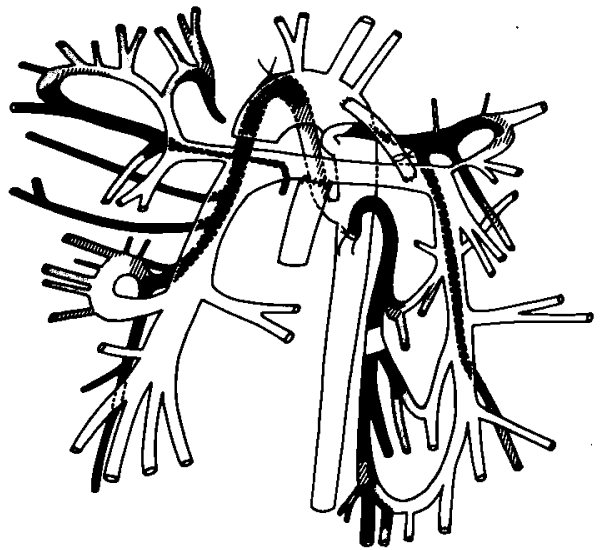

$1 C$

Fig. 1. Schematic drawings of different examples of collateral supply. A, An example of single anastomosis between the collateral artery and the pulmonary artery. B, Multiple simple anastomoses between the collateral arteries and the pulmonary arteries are present. $\mathbf{C}$, The outflow tract of the right ventricle is surgically reconstructed and a systemic-pulmonary shunt is ligated. Complex loop anatomoses between the collateral arteries and pulmonary arteries. The various graphic markings indicate the muscular (large dots), musculoelastic (striped), elastic (white), and loose-elastic (small dots) segments. logic features of the pulmonary arteries, ductus arteriosus, bronchial arteries, and the systemic-pulmonary collateral arteries were evaluated in microscopic sections taken from consecutive blocks that were taken along the branches. The sections were stained with hematoxylin-eosin and van Gieson elastic staining. These sections were restudied and compared with the working drawings. ${ }^{2}$ For the present study some of these drawings were modified by the medical artist.

Definitions. We used the following definitions to describe the various types of arteries ${ }^{26,27}$ : An elastic artery contains more than seven elastic lamellae in the tunica media. Between the elastic lamellae smooth muscle cells are present. A loose elastic artery is a thin-walled elastic vessel with fewer than seven elastic lamellae alternating with smooth muscle cells. A muscular artery shows a thick muscular tunica media with only a few elastic lamellae. A musculoelastic artery is a large muscular vessel with many elastic lamellae in the tunica media. It is often present as a transitional segment between a muscular and an elastic artery. A ductus arteriosus is a muscular artery, but it is distinguished by the absence of an external elastic lamina in the tunica adventitia. The number, origin, and course of the complete muscular bronchial arteries are variable. The two left bronchial arteries mainly arise from the anterior wall of the descending aorta, and the right bronchial artery arises from the first posterior intercostal artery or the upper left bronchial artery. ${ }^{27-30}$ The branches of the pulmonary arteries follow the course of the bronchi and show an elastic tunica media, if larger than $1 \mathrm{~mm}$.

The anastomosis between a systemic-pulmonary collateral artery and the pulmonary system can be identified only in gross dissection when the (non-)confluent central pulmonary arteries are present. The systemic-pulmonary collateral arteries can communicate with the central pulmonary arteries by one single anastomosing vessel or by multiple vessels (definition: multiple simple anastomoses). The third possibility consists of one systemic-pulmonary collateral artery communicating more than once with the pulmonary artery system (definition: complex loop anastomoses). In addition, the site of anastomosis of a systemic-pulmonary collateral artery with the intrapulmonary system, when the central pulmonary artery is absent, can be detected in the Mayo collection from the transition of a muscular or musculoelastic tunica media into a complete elastic media.

Statistical methods. Discrete variables were compared with the $\chi^{2}$ test. A $p$ value of 0.05 or less was considered to represent statistical significance.

\section{Results}

Confluent central pulmonary arteries and systemicpulmonary collateral arteries were present in $74 \%$ (23/ 31 ) of all specimens studied. Eight specimens (26\%) contained systemic-pulmonary collateral arteries and nonconfluent or absent central pulmonary arteries. In specimens with confluent central pulmonary arteries, the systemic-pulmonary collateral arteries were connected to the pulmonary arteries by a single anastomosis ( 14 cases; Fig. 1, $A$ ), multiple simple anastomoses ( 5 cases; Fig. 1, $B$ ), or by complex loop anastomoses, that is, with more than one anastomosis (4 cases; Fig. 1, C).

Most of the systemic-pulmonary collateral arteries arose from the descending aorta $(68 \%, 83 / 122)$ and the 
aortic arch $(16 \%, 19 / 122)$. The other origins were the subclavian artery ( 5 cases), abdominal aorta ( 2 cases), and the coronary artery $(1$ case). The origin of 12 systemic-pulmonary collateral arteries $(10 \%)$ was unknown because of incomplete surgical data. In case of a left or right aortic arch, the number of systemic-pulmonary collateral arteries to the left and right lungs did not differ significantly.

Fifteen (12\%) of all collateral arteries studied $(n=122)$ developed extrapulmonary branches. In 13 cases $(87 \%)$ these collaterals supplied branches to both lungs, whereas only two extrapulmonary branching collateral arteries supplied either a left or a right lung.

In the Pittsburgh collection only the course of the systemic-pulmonary collateral arteries relative to the bronchi could be studied. Their course along the bronchi was variable. The proximal parts of the collateral arteries were mainly located posterior $(59 \%, 22 / 39)$ and superior $(31 \%, 12 / 39)$ to the bronchi. All possible courses of the systemic-pulmonary collateral arteries on the first branches of the bronchi in the left and right lungs were present. No differences were observed between the courses of the systemic-pulmonary collateral arteries to the left and right lungs.

In $71 \%$ of the systemic-pulmonary collateral arteries $(59 / 83)$ of the 20 specimens of the Mayo collection, the proximal part was muscular or musculoelastic. In the other collateral arteries (29\%), the proximal part was elastic. Only two systemic-pulmonary collateral arteries (2\%) were completely elastic. The remaining $98 \%$ had a muscular segment or a musculoelastic segment or both. Seventy-three percent $(61 / 83)$ of the systemic-pulmonary collateral arteries had a muscular segment ranging from a very short, noncircular segment to a very long segment. Of the remaining 22 specimens without a muscular segment, 20 had a musculoelastic segment.

In four specimens with complex loop anastomoses, $93 \%$ of the total number of systemic-pulmonary collateral arteries $(14 / 15)$ had long muscular segments or were completely muscular (Fig. 1, C). One of these collateral arteries (7\%) contained a short muscular segment. In all other specimens the histologic features of a systemic-pulmonary collateral artery were not related to its course, branching pattern, type of anastomosis (single or multiple simple), presence of a central pulmonary artery, place of connection with the intrapulmonary arteries, or total number of collaterals in the specimens.

In 29 of 31 autopsy specimens studied, neither a ductus arteriosus nor a ductus ligament was found (one unknown because of absent surgical data). In one case the vessel supplying the entire left lung arose from the subclavian artery, whereas the left central pulmonary artery was absent. Without histologic data the possibility that this vessel was a patent ductus arteriosus could not be evaluated.

Ten systemic-pulmonary collateral arteries arose from the aortic arch or from the contralateral subclavian artery to supply one lung, without communicating with the central pulmonary artery system. This origin and course are suggestive of the presence of a ductus arteriosus, but the typical ductal histologic characteristics, lacking an external elastic lamina, were not found. On the contrary, all the muscular (Fig. 2, $A$ ) and musculoelastic (Fig. 2, B) collateral arteries showed external elastic laminae and a relatively thin tunica media with regard to their lumina.

Bronchial arteries (nutritive arteries) that arose from the thoracic aorta or intercostal arteries were not found in any of the specimens. In the Pittsburgh collection, nutritive branches from the systemic-pulmonary collateral arteries could not be identified. Nutritive arteries from the first to fourth branches of the collateral arteries to the bronchi, however, were observed in 11 of the 20 specimens $(55 \%)$ of the Mayo collection. The mean number of nutritive tributaries arising from these systemic-pulmonary collateral arteries was 1.8 (range 1 to 5). Sixty-three percent $(25 / 40)$ of these nutritive arteries arose from the muscular segments of the systemicpulmonary collateral arteries. The other nutritive branches arose from the elastic $(n=8)$, musculoelastic $(n=4)$, and loose elastic $(n=3)$ segments. All 4 specimens with complex loop anastomoses to confluent central pulmonary arteries, which show long muscular segments (Fig. $1, C)$, had nutritive arteries to the bronchi.

Intimal proliferations were present in all types of systemic-pulmonary collateral arteries. The difference in the frequency of intimal proliferations among muscular segments $(32 \%, 20 / 62)$, elastic segments $(23 \%, 21 / 90)$, and musculoelastic segments $(24 \%, 18 / 75)$ was not significant. In $47 \%$ (39/83) of the systemic-pulmonary collateral arteries, the tunica intima was thickened. In the collateral arteries that had been surgically ligated $(n=21)$, intimal thickening and complete obliteration of the lumen was present in 12 cases (57\%).

The histologic features of the intimal proliferations varied highly. Most of the proliferations were muscular. The severe intimal proliferations did not contain a subendothelial lamina, and the internal elastica lamina had disappeared or was fragmented (Fig. 3, $A$ ). Many of the mild intimal proliferations had a subendothelial lamina (Fig. 3, $B$ ), as seen in a persistent ductus arteriosus.

\section{Discussion}

Large differences in age and patient history exist between the collections of the Children's Hospital of Pittsburgh and the Mayo Clinic. The Pittsburgh collection is characterized by a young age of the patients, who 


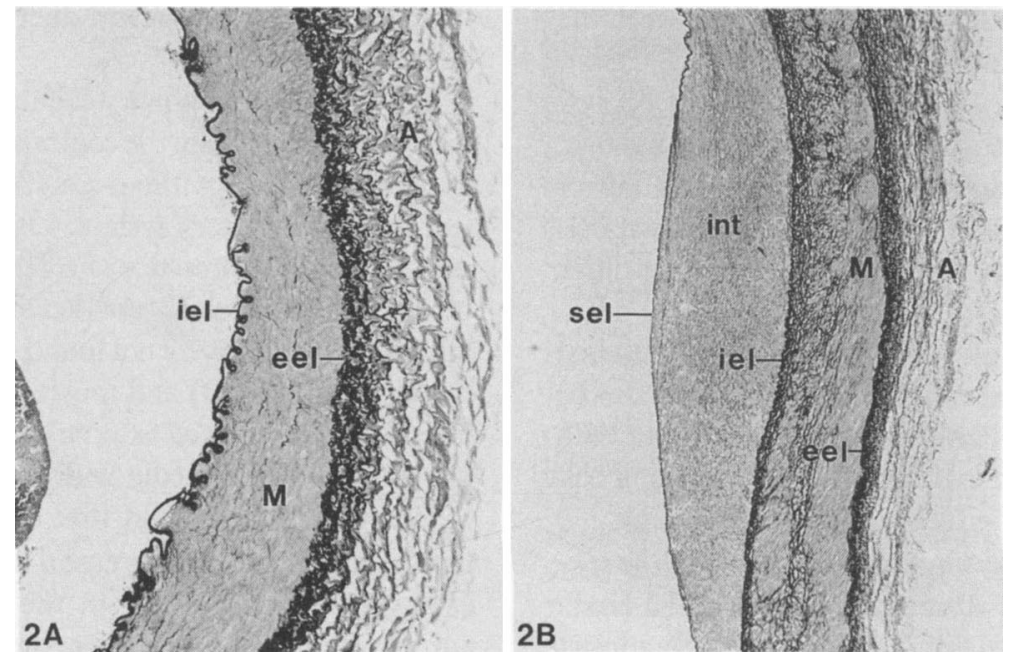

Fig. 2. A, Micrograph of a systemic-pulmonary collateral artery with a muscular segment. Note the thin internal elastic lamina (iel) and the thick external elastic lamina (eel). B, Micrograph of a systemic-pulmonary collateral artery with a musculoelastic segment. Both the internal (iel) as the external laminae (eel) are thick. Subjacent to the endothelium of the large intimal proliferation (int) an additional subendothelial elastic lamina (sel) is present. $A$, Adventitia, $M$, media. Elastic-van Gieson stain.

had not been operated on or had died within 3 days after the operation. The Mayo Clinic collection includes a large number of relatively old patients, who underwent surgery. Notwithstanding this dissimilarity between the two collections, significant differences in the arterial supply to the lungs were not observed. The age of the patients and the surgical interventions in the Mayo Clinic collection may have biased our observations on the presence or absence of a (ligamentous) ductus arteriosus and the extent of intimal thickening and obliteration, and it may also have changed the information on the extent of nutritive or bronchial arteries.

The studied autopsy specimens of the Mayo collection were published before by Liao and coworkers. ${ }^{2}$ They described 31 cases of pulmonary atresia with a ventricular septal defect. Twenty (20/31) involved large systemic-pulmonary collateral arteries. In this group only one ductus arteriosus was described and no ligamentous ductus were seen. In the remaining 11 cases (11/31) without large collateral arteries, a ductus arteriosus was always found. In our study, only the 20 cases with large systemic-pulmonary collateral arteries were reinvestigated. This revealed that the ductus arteriosus described by Liao in this group lacked the typical histologic features of a ductus, because it had an external elastic lamina and thus could not be differentiated from other muscular systemic-pulmonary collateral arteries.

- The macroscopic study of the Pittsburgh collection did not reveal the coexistence of a ductus arteriosus or a lig- ament with large systemic-pulmonary collateral arteries (two cases unknown.). Our data, therefore, suggest that the combination of a ductus arteriosus and large systemic-pulmonary collateral arteries does not occur. Data from the literature are less conclusive. Thiene and coworkers ${ }^{5}$ described the coexistence of a ductus with large systemic-pulmonary collateral arteries, but in general not to the same lung. In some cases, a ductus and collateral arteries have been mentioned to run to the same lung, but then they supply different pulmonary units. ${ }^{1}$ The vessel depicted (Fig. 1, page 348) in the work of Frescura and associates, ${ }^{1}$ however, is not typical of a ductus arteriosus and, in our opinion, might well be a musculoelastic systemic-pulmonary collateral artery. The macroscopic work of Thiene and coworkers ${ }^{5}$ is not substantiated by histologic evaluation.

The present results show that the systemic-pulmonary collateral arteries could not be classified according to their course relative to the trachea and the first branches of the bronchi. No differences were observed in either number or course of the collateral arteries between the left and right lungs. Although the proximal part of the collateral arteries is usually situated along the posterior surface of the bronchi, like the bronchial arteries, this does not indicate that the systemic-pulmonary collateral arteries must be considered to be enlarged bronchial arteries, ${ }^{7}$ because most of them are already positioned posteriorly by their origin from the descending aorta. The histologic characteristics of the systemic-pulmonary collateral arteries 

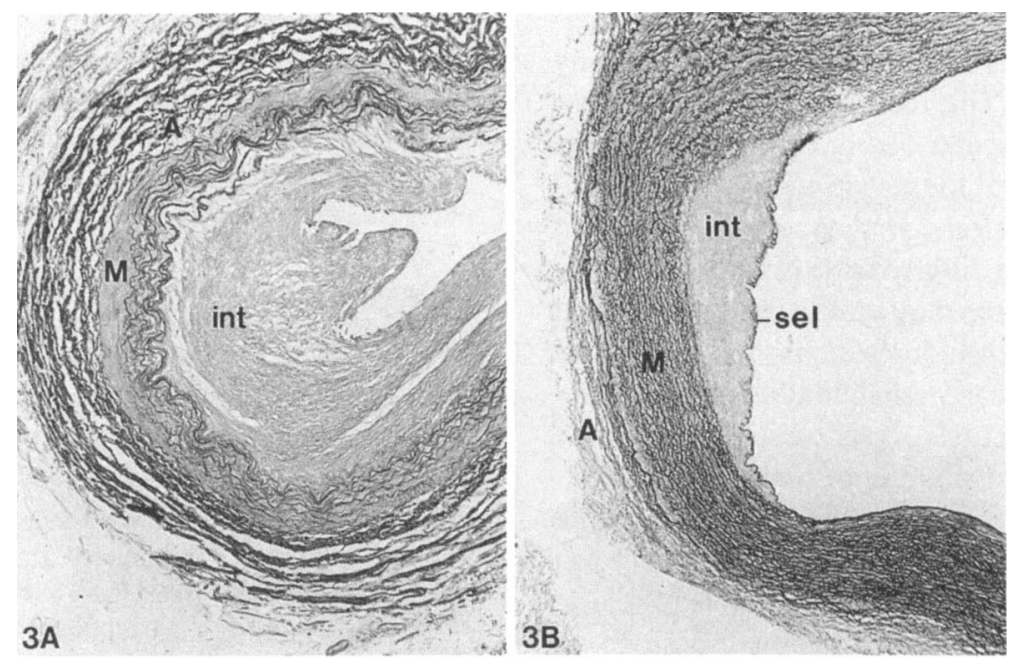

Fig. 3, A, A severe intimal proliferation (int), which is almost obstructive, without a subendothelial elastic lamina in a musculoelastic systemic-pulmonary collateral artery. B, A subendothelial elastic lamina (sel) is present in the mild intimal proliferation (int) of a musculoelastic to elastic systemic-pulmonary collateral artery. $A$, Adventitia; $M$, media. Elastic-van Gieson stain.

vary along their course to the lungs, but almost all contain a muscular or a musculoelastic segment. Except in the specimens with complex loop anastomoses, which were completely muscular, no relationships were found between the histologic characteristics of systemic-pulmonary collateral arteries and their origin, course, branching patterns, or anastomoses to the pulmonary arteries.

The nutritive branches arising from some systemicpulmonary collateral arteries suggest that these are enlarged bronchial arteries. Nutritive branches, however, arise not only from systemic-pulmonary collateral arteries that resemble the typical histologic characteristics of the bronchial arteries, such as those with complex loop anastomoses, but from all histologic types of segments.

Proposed classifications of different types of systemicpulmonary collateral arteries ${ }^{9,19}$ are based on embryologic theories. ${ }^{15-17}$ These theories suggest a separate development of the (intra- and extra-) pulmonary arteries and the bronchial arteries, before the two systems start to anastomose. Classic embryologic observations, however, do not explain the great variability encountered in origin, course, arborization, and possible anastomoses with the pulmonary arteries of the systemic-pulmonary collateral arteries. From our recent study on the normal development of the pulmonary and bronchial vasculature, ${ }^{31}$ it can be deduced that collateral artery supply develops from one splanchnic vascular plexus. This plexus, which covers the developing bronchi, trachea, and esophagus, gives rise to all types of lung vessels. During two periods separated by an interposed period, the plexus communi- cates by luminal connections developing with the aorta and the intercostal arteries. During the first period the caudal part of the splanchnic plexus is temporarily connected to the aorta. The pulmonary and bronchial arteries cannot be recognized as separate vessels with lumina within the plexus at that time. When these aortopulmonary connections disappear, pulmonary arteries with lumina start to develop in the splanchnic plexus. In the second, extended period when the pulmonary and aortic orifices are separated by the aortopulmonary septum, the pulmonary arteries are recognizable as vessels with lumina around the developing bronchi. The remnants of the splanchnic plexus connect again with the descending aorta. These communicating vessels with lumina ultimately give rise to the bronchial arteries. During further fetal development, the bronchial arteries remain connected with the pulmonary vessels by bronchopulmonary anastomoses. Because both sets of aortopulmonary connections originate subsequently from the same splanchnic plexus, this will not lead to an easy differentiation in the postnatal period between the various collateral arteries.

Surgical implications. Reconstructive surgery (e.g., unifocalization procedures) aims at the incorporation in the pulmonary vasculature of all systemic-pulmonary collateral arteries of importance. On the sole basis of pragmatic arguments, this usually means the incorporation of systemic-pulmonary collateral arteries providing the perfusion of more than a single pulmonary segment. ${ }^{24}$ In this regard, bronchial arteries are usually too small to be incorporated in the reconstruction. However, surgical 
exposure could be inadequate because of overlying bronchial arteries. The latter can be sacrificed without any obvious clinical effect. The reconstruction of an unobstructed pulmonary vascular bed of optimal capacity is considered to be essential to provide adequate right ventricular decompression after complete repair. ${ }^{32}$ Persistent or developing stenoses at different sites of the reconstructed pulmonary arterial tree may lead to less than optimal results and may even preclude the final step of complete repair. ${ }^{24,32}$ In addition early rehabilitation of the pulmonary arterial tree by increasing blood flow of low pressure seems to improve the possibilities of complete repair. ${ }^{33}$

On the basis of our morphologic and histologic data showing the variable origins of systemic-pulmonary collateral arteries being reflected in their variable histologic characteristics and the subsequent predisposition to stenosis or even occlusion, it is understandable that the surgical reports in unifocalization procedures cannot successfully predict the suitability of a specific systemic-pulmonary collateral artery for incorporation in the newly constricted pulmonary arterial bed.

In this setting, the preparing steps leading to repair should probably be done early in life, ${ }^{33,34}$ to profit from tissue pliability in young patients and, more important, to prevent the complications of longstanding abnormal perfusion of lung segments. ${ }^{20,25}$ However, risk-adjusted, time-related probabilities of morbidity and mortality are not yet available. ${ }^{20}$ Nevertheless, adequate, preferably complete, unifocalization is therefore a prerequisite for successful repair. ${ }^{20-22}$ In this regard, discrete stenoses of the pulmonary arterial bed may be treated at any stage by surgery or percutaneous balloon dilatation ${ }^{20,21}$ or stenting. ${ }^{35}$

These surgical and invasive cardiologic attempts definitely show the feasibility of incorporating these systemic-pulmonary collateral arteries into an adequately functioning pulmonary vascular bed, despite the uncertainties of the long-term fate of these collateral arteries and despite the risk of progressive stenoses in their vascular bed. On-going anatomic and surgical efforts are essential to improve the results of surgical attempts to treat pulmonary atresia with ventricular septal defect and pulmonary circulation dependent on systemic-pulmonary collateral arteries.

We appreciate the contribution of the Division of Anatomic Pathology, Mayo Clinic, and especially acknowledge the work of Pui-Kan Liao, MD, currently of The Children's Hospital of New Jersey, Newark, New Jersey. J. R. Zuberbuhler, MD, of the Children's Hospital of Pittsburgh, Department of Pathology, is thanked for his hospitality and the permission to study autopsy specimens. Moreover, we are indebted to J. Lens for his photographic work and to S. B. Blankevoort for his drawings.

\section{R E F E R E N C ES}

1. Frescura C, Talenti E, Pellegrino PA, Mazzucco A, Faggian G, Thiene G. Coexistence of ductal and systemic pulmonary arterial supply in pulmonary atresia with ventricular septal defect. Am J Cardiol 1984;53:348-9.

2. Liao P, Edwards WD, Julsrud PR, Puga FJ, Danielson GK, Feldt RH. Pulmonary blood supply in patients with pulmonary atresia and ventricular septal defect. J Am Coll Cardiol 1985;6:1343-50.

3. Rossi M, Rossi Filho R, HoSY.Solitary arterial trunk with pulmonary atresia and arteries with supply to the left lung from both an arterial duct and systemic-pulmonary collateral arteries. Int J Cardiol 1988;20:145-8.

4. Sotomora RF, Edwards JE. Anatomic identification of so-called absent pulmonary artery. Circulation 1978;57: 624-33.

5. Thiene G, Bortolotti U, Gallucci V, Valente ML, Volta SD. Pulmonary atresia with ventricular septal defect. Br Heart J 1977;39:1223-33.

6. Edwards JE, McGoon DC. Absence of anatomic origin from heart of pulmonary arterial supply. Circulation 1973;47:393-8.

7. Jefferson K, Rees S, Somerville J. Systemic arterial supply to the lungs in pulmonary atresia and its relation to pulmonary artery development. Br Heart J 1972;34:418-27.

8. Chesler E, Matisonn R, Beck W. The assessment of the arterial supply to the lungs in pseudotruncus arteriosus and truncus arteriosus type IV in relation to surgical repair. Am Heart J 1974;88:542-52.

9. Haworth SG, Macartney FJ. Growth and development of pulmonary circulation in pulmonary atresia with ventricular septal defect and major aortopulmonary collateral arteries. Br Heart J 1980;44:14-24.

10. McGoon MD, Fulton RE, Davis GD, Ritter DG, Neill CA, White RI. Systemic collateral and pulmonary artery stenosis in patients with congenital pulmonary valve atresia and ventricular septal defect. Circulation 1977;56:473-9.

11. Haworth SG, Rees PG, Taylor JFN, Macartney FJ, de Leval M, Stark J. Pulmonary atresia with ventricular septal defect and major aortopulmonary collateral arteries: effect of systemic pulmonary anastomosis. $\mathrm{Br}$ Heart $\mathbf{J}$ 1981;45:133-41.

12. Tadavarthy SM, Klugman J, Castaneda-Zuniga WR, Nath PH, Amplatz K. Systemic-to-pulmonary collaterals in pathological stages. Radiology 1982;144:55-9.

13. Zureikat HY. Collateral vessels between the coronary and bronchial arteries in patients with cyanotic heart disease. Am J Cardiol 1980;45:599-603.

14. Macartney F, Deverall P, Scott O. Haemodynamic characteristics of systemic arterial blood supply to the lungs. $\mathrm{Br}$ Heart J 1973;35:28-37.

15. Boyden EA. The time lag in the development of bronchial arteries. Anat Rec 1970A;166:611-4.

16. Boyden EA. The developing bronchial arteries in a fetus of the twelth week. Am J Anat 1970B;129:357-68.

17. Huntington GS. The morphology of the pulmonary artery in the mammalia. Anat Rec 1919;17:165-89. 
18. Burrows PE, Freedom RM, Rabinovitch M, Moes CAF. The investigation of abnormal pulmonary arteries in congenital heart disease. Radiol Clin North Am 1985;23:689717.

19. Rabinovitch M, Herrera-DeLeon V, Casteneda AR, Reid L. Growth and development of the pulmonary vascular bed in patients with tetralogy of Fallot with or without pulmonary atresia. Circulation 1981;64:1234-48.

20. Kirklin JW, Barratt-Boyes BG. Cardiac surgery. 2nd ed. New York: Churchill Livingstone, 1993;942-73.

21. Puga FJ, Leoni FE, Julsrud PR, Mair DD. Complete repair of pulmonary atresia, ventricular septal defect, and severe peripheral arborization abnormalities of the central pulmonary arteries. J Thorac CARdiovasC Surg 1989;98: 1018-29.

22. Sullivan ID, Wren C, Stark J, de Leval MR, Macartney FJ, Deanfield JE. Surgical unifocalization in pulmonary atresia and ventricular septal defect. A realistic goal? Circulation 1988;78(Suppl):III5-13.

23. Haworth SG. Collateral arteries in pulmonary atresia with ventricular septal defect: a precarious blood supply. $\mathrm{Br}$ Heart J 1980;44:5-13.

24. Iyer KS, Mee RBB. Staged repair of pulmonary atresia with ventricular septal defect and major systemic to pulmonary artery collaterals. Ann Thorac Surg 1991;51:6572 .

25. Sawatari K, Imai Y, Kurosawa H, Isomatsu Y, Momma K. Staged operation for pulmonary atresia and ventricular septal defect with major aortopulmonary collateral arteries. J Thorac Cardiovasc Surg 1989;98:738-50.

26. Junqueira LC, Carneiro J. Basic histology. 4th ed. Los Altos: Lange Medical Publications, 1983.
27. Warwick R, Williams PL. Gray's anatomy. 35 th ed. London: Longman, 1973.

28. Liebow AA. Patterns of origin and distribution of the major bronchial arteries in man. Am J Anat 1965;117:19-32.

29. Marchand P, Gilroy JC, Wilson VH. An anatomical study of the bronchial vascular system and its variations in disease. Thorax 1950;5:207-21.

30. Schreinemakers HHJ, Weder W, Miyoshi S, et al. Direct revascularization of bronchial arteries for lung transplantation: an anatomical study. Ann Thorac Surg 1990;49:4454.

31. DeRuiter MC, Gittenberger-de Groot AC, Poelmann RE, VanIperen L, Mentink MMT. Development of the pharyngeal arch system related to the pulmonary and bronchial vessels in the avian embryo: with a concept on systemicpulmonary collateral artery formation. Circulation 1993; 87:1306-19.

32. Puga FJ. Unifocalization for pulmonary atresia with ventricular septal defect. Ann Thorac Surg 1991;51:8-9.

33. Rome JJ, Mayer JE, Castaneda AR, Lock JE. Tetralogy of Fallot with pulmonary atresia: rehabilitation of diminutive pulmonary arteries. Circulation 1993;88:1691-8.

34. Shanley CJ, Lupinetti FM, Shah NL, et al. Primary unifocalization for the absence of intrapericardial pulmonary arteries in the neonate. J Thorac Cardiovasc Surg 1993;106:237-47.

35. O'Laughlin MP, Perry SB, Lock JE, Mullins CE. Use of endovascular stents in congenital heart disease. Circulation 1991;83:1923-39. 